\title{
Loading and evaluation of meloxicam and atorvastatin in carrageenan microspherical aerogels particles
}

\author{
Mohammad Alnaief ${ }^{*}$, Rana Obaidat ${ }^{2}$, Hadeia Mashaqbeh ${ }^{2}$ \\ ${ }^{1}$ Department of Pharmaceutical and Chemical Engineering, Faculty of Applied Medical Sciences, German Jordanian University, Amman, Jordan. \\ ${ }^{2}$ Department of Pharmaceutical Technology, Faculty of Pharmacy, Jordan University of Science and Technology, Irbid, Jordan.
}

\begin{tabular}{l}
\hline ARTICLE INFO \\
\hline Received on: 07/10/2018 \\
Accepted on: 20/11/2018 \\
Available online: $31 / 01 / 2019$ \\
\\
\hline Key words: \\
Carrageenan aerogel, \\
meloxicam, atorvastatin, \\
supercritical fluid technology, \\
drug loading.
\end{tabular}

\begin{abstract}
In this work, the potential of using microspherical aerogel particles based on commercial carrageenan as a drug vehicle was evaluated. Carrageenan hydrogel microparticles were prepared following the emulsion gelation approach. After the successive solvent exchange, supercritical $\mathrm{CO}_{2}$ drying procedure was employed to obtain aerogel microspherical particles. Meloxicam and atorvastatin (class II drug) were loaded into the aerogel matrix by adsorption from their corresponding supercritical $\mathrm{CO}_{2}$ solution. All preparations were characterized by their physicochemical properties. In vitro drug released was investigated for the drug-aerogel formulation to assist the effect of aerogel technology on the release profile of the targeted drug. Meloxicam and atorvastatin model drugs maintained their crystalline structure. Significant enhancement in the release profile of meloxicam after loading in the carrageenan aerogel can be related to de-aggregation of meloxicam inside the particle, while no enhancement in atorvastatin release was observed. Results were indicative of a failure in the loading of atorvastatin inside the carrageenan particle at the selected experimental processing parameters.
\end{abstract}

\section{INTRODUCTION}

Carrageenans are naturally renewable polysaccharide originated from red seaweed. The high molecular weight of carrageenans composed of repeating units of 1,3 -linked $\beta$-dgalactose and 1,4-linked $\alpha$-d-galactose with different degree of sulfatation. The type of carrageenans depends mainly on the estersulfate group's contents and position (Necas and Bartosikova, 2013). The main common types of carrageenans are $\kappa$-carrageenan, $i$-carrageenan, and $\lambda$-carrageenan. The main difference between these main groups is the number of the sulfate group which is one, two, and three for $\kappa$-carrageenan, í-carrageenan, and $\lambda$-carrageenan, respectively (Campo et al., 2009). In the presence of monocations or divalent cations, carrageenan tends to form a gel due to the anionic nature of the half-ester sulfate group (Santo et al., 2009). Carrageenan considered as non-toxic and non-irritating substance,

\section{"Corresponding Author}

Mohammad Alnaief, Department of Pharmaceutical and Chemical Engineering, Faculty of Applied Medical Sciences, German Jordanian University, Amman, Jordan.E-mail: mohammad.alnaief@gju.edu.jo which allow their use in many pharmaceutical applications (Liu et al., 2015; Rowe et al., 2009).

Several studies reported the use of carrageenan for drug delivery applications (Dafe et al., 2017; El-Aassar et al., 2015; Li et al., 2014; Liu et al., 2015). Carrageenan-based preparations can be used in different dosage forms such as suspensions, emulsions, creams, gels, lotions, eye drops, suppositories, capsules, and tablets (Guan et al., 2017; Rowe et al., 2009). Several studies have been shown that due to the Carrageenan adhesion properties, it can be used in oral and buccal formulations for drug delivery preparations (Hanawa et al., 2004; Martins et al., 2015). Carrageenan also used to enhance the bioavailability of poorly soluble drugs (Varghese et al., 2014). Carrageenan also reported in microencapsulation of proteins (Hezaveh and Muhamad, 2012; Patil and Speaker, 2000) and probiotic bacteria (Jonganurakkun et al., 2006). In addition, several researchers reported that the use of carrageenan for anticancer, gene, cell, and peptide drug delivery (Gu et al., 2015; Guan et al., 2017; Karimi et al., 2018; Ling et al., 2016; Santo et al., 2009; Tan and Lee, 2015).

Aerogels are class of nanoporous solid materials with a large porosity and open pore structure. Due to their porosity (up to 
$99 \%)$, they are an ultralight solid material with a density $(0.003-$ $0.15 \mathrm{~g} \cdot \mathrm{cm}^{-3}$ ) and large specific surface area (up to $1,000 \mathrm{~m}^{2} \cdot \mathrm{g}^{-1}$ ) (Alnaief, 2011; Maleki et al., 2016; Smirnova, 2015). Aerogels can be produced from inorganic, organic, or organic-inorganic precursors, which gave them a flexible surface chemistry and allow them to be used in huge number of applications such as insulation, food technology, catalysis, environmental, and life sciences applications (Gurikov and Smirnova, 2017; Maleki, 2016; Maleki and Hüsing, 2018; Stergar and Maver, 2016; Ulker and Erkey, 2014). Being renewable, abundant, biodegradable, and biocompatible, polysaccharide-based aerogels have attracted increasingly attention in the field of tissue engineering and drug delivery (Barros et al., 2016; García-González et al., 2011; 2015; Martins et al., 2015; Obaidat et al., 2018).

Meloxicam and atorvastatin drugs classified as biopharmaceutical classifications class II corresponding to its high permeability and low solubility. Meloxicam (4-hydroxy-2-methylN-5-methyl-2-thiazolyl-H-1, 2-benzothiazine-3-carboxamide 1, 1-dioxide) is an oxicam derivative. It is part of the enolic group of non-steroidal anti-inflammatory drugs. It has an antipyretic and analgesic action (El-Badry, 2011; Luger et al., 1996). Atorvastatin is a synthetic lipid-lowering agent which selectively and competitively inhibits the enzyme 3-hydroxy-3-methylglutarylcoenzyme (de Queiroz Ribeiro et al., 2017; Sonje et al., 2010).

The aim of this work is to evaluate carrageenan microspherical aerogel particles as a potential drug carrier for meloxicam and atorvastatin. Microspherical aerogel particles based on carrageenan were prepared following our previous report (Alnaief et al., 2018). The model drugs were loaded on the aerogel particles by adsorption from their corresponding supercritical carbon dioxide solution. The prepared formulations were characterized for their physicochemical properties and in vitro drug released was evaluated.

\section{EXPERIMENTAL}

\section{Material}

Carrageenan suitable for gel preparation (lot number; SLBK3896V), and span 80 was acquired from Sigma Aldrich. Absolute ethanol was purchased from Solvochem, Holland. Carbon dioxide $\left(\mathrm{CO}_{2}\right)$ was provided by the Jordanian Gas Co., Amman, Jordan. Water [High performance liquid chromatography (HPLC) grade] was provided by LABCHEM, USA. Potassium chloride extra pure [British Pharmacopeia (BP) United States Pharmacopeia (USP)] and potassium dihydrogen phosphate were enquired from AZ chem for chemicals. Potassium phosphate dibasic was purchased from Xilong chemical industry, China. Atorvastatin calcium was supplied by Biocon, Bangalore, India. Meloxicam was kindly donated by the Jordanian Pharmaceutical Manufacturing Company, Na'or, Jordan.

All chemicals were used as supplied without further modification.

\section{Methodology}

\section{Preparation of the carrageenan aerogel microparticles}

Microspherical carrageenan aerogel particles were prepared following the procedure reported in previous work
(Alnaief et al., 2018). Briefly, a suitable amount of carrageenan suitable for gelation was dissolved in water to achieve $2 \mathrm{wt} \%$ carrageenan solution. Carrageenan solution was then heated gradually to $90^{\circ} \mathrm{C}$ and left under stirring for 30 minutes. After that, the heated carrageenan was tipped into a to $200 \mathrm{ml}$ preheated paraffinic oil containing $2 \mathrm{wt} \%$ of $\operatorname{Span}^{\circledR} 85$ and mixed using an overhead mixer at 3,000 rpm for 15 minutes. The sol droplet formed during the emulsification was then crosslinked using $\mathrm{KCl}$ solution. After the addition of the crosslinker, the dispersion kept under mixing at 3,000 rpm for 15 minutes and at $200 \mathrm{rpm}$ for further 30 minutes. The prepared hydrogel was then converted to hydro-alcoholic gel using successive solvent exchange steps. The solvent exchange steps were $20 \%, 40 \%$, $60 \%$, and $80 \%$ ethanol: water and two times $100 \%$ ethanol, each step was allowed to mix for 1 hour. Finally, the alcoholic gel microparticles were extracted using supercritical carbon dioxide at $100 \mathrm{bar}, 40^{\circ} \mathrm{C}$ and at a constant flow rate of $100 \mathrm{~g} / \mathrm{minute}$ for 4 hours (Alnaief et al., 2018).

Carrageenan aerogel microparticles were characterized for their surface area, porosity, and pore volume using nitrogen sorption technique (NOVA 2000). The particle size distribution was obtained using laser particle size analyzer (Microtrac S3500, USA). Scanning electron microscope (SEM) images were taken for the prepared particles at different resolution (Quanta FEG 450, FEI, USA). All used techniques are reported in the previous study.

\section{Loading of the prepared aerogels with the model drugs}

The drug was added to the aerogel after drying directly, after mixing, the sample was placed in a preheated $70 \mathrm{ml}$ stainless vessel at $40^{\circ} \mathrm{C} . \mathrm{CO}_{2}$ was introduced to vessel from the top until the pressure reached 100 bar using double piston high-pressure $\mathrm{CO}_{2}$ pump. The condition was kept for 2 hours. After that, $\mathrm{CO}_{2}$ was release slowly to a fume hood.

\section{Drug content percent determination}

To determine drug content percent, $10 \mathrm{mg}$ of each loaded sample was dissolved in $25 \mathrm{ml}$ phosphate buffer $\mathrm{pH} 7.2$, and then further diluted to get suitable concentration. The drug concentration was measured using UV calibration curve at $\lambda_{\max }: 361$ and $241 \mathrm{~nm}$ of meloxicam and atorvastatin, respectively. The drug content percent was calculated by using the following equation:

$$
\text { Drug content } \%=\frac{\text { actual drug content }}{\text { theoritical drug content }} \times 100 \%
$$

\section{Characterizations of the prepared formulation}

\section{Fourier transform-infrared spectroscopy}

The Fourier transform-infrared (FT-IR) spectra of the prepared aerogel microparticles, raw drug, and their physical mixtures (PM) were obtained using IRAffinity-1 Spectrophotometer (Shimadzu, Japan) with $\mathrm{KBr}$ as a reference by mixing the particles with potassium bromide powder and grinding it using mortar and pestle until a well-dispersed sample was obtained. A small amount well-dispersed was then analyzed using FT-IR over a frequency range of $4,750-250 \mathrm{~cm}^{-1}$ and $0.04 \mathrm{~cm}^{-1}$ resolution. 


\section{Differential scanning calorimetric analysis}

Differential scanning calorimetric (DSC) thermograms of each of the prepared microparticles, raw materials, and PM of raw materials obtained using a Shimadzu DSC-50. Approximately, $5 \mathrm{mg}$ taken from each sample and heated in sealed aluminum pans under nitrogen at a range of $25^{\circ} \mathrm{C}-250^{\circ} \mathrm{C}$ and a rate of $10^{\circ} \mathrm{C} /$ minute. An empty sealed aluminum pan used as a reference.

\section{Thermogravimetric analysis}

Thermogravimetric analysis (TGA) thermograms of each of the prepared microparticles, raw materials, and PM of raw materials were obtained using a Shimadzu TGA-50 under nitrogen at a range of $25^{\circ} \mathrm{C}-350^{\circ} \mathrm{C}$ and a rate of $10^{\circ} \mathrm{C} /$ minute.

\section{Powder X-ray diffraction}

The X-ray diffraction patterns for the prepared microparticles, raw materials, and PM of raw materials were recorded (Powder X-ray diffractometer, Ultima IV X-ray diffractometer, Rigaku, Japan) using cobalt radiation at a voltage of $40 \mathrm{kV}$ and a current of $30 \mathrm{~mA}$.

In vitro drug release study

All dissolution tests were performed following the standard procedures from the United State Food and Drug Administration (Dissolution Methods, 2018).

\section{Meloxicam}

A sample which contains $15 \mathrm{mg}$ of meloxicam loaded sample was accurately weighed. The dissolution tests were performed using USP apparatus II (rotating paddle) at $75 \mathrm{rpm}$ and $37^{\circ} \mathrm{C}$ using $900 \mathrm{ml}$ of $0.2 \mathrm{M}$ of potassium phosphate buffer with adjusted $\mathrm{pH}$ of 7.5. At predetermined time intervals, $5 \mathrm{ml}$ aliquot was taken at predetermined time intervals, filtered through $0.45-\mu \mathrm{m}$ membrane filtered and analyzed by UV spectrophotometer at $361 \mathrm{~nm}$. An equal volume of dissolution media was replaced to maintain the sink condition of the dissolution medium.

\section{Atorvastatin}

A sample which contains $20 \mathrm{mg}$ of atorvastatin-loaded sample was accurately weighted. The dissolution test was performed using USP apparatus II (rotating paddle) at $75 \mathrm{rpm}$ and $37^{\circ} \mathrm{C}$ using $900 \mathrm{ml} 0.05$ phosphate buffer solution ( $\mathrm{pH} \mathrm{6.8)}$. At a predetermined times interval, $5 \mathrm{ml}$ aliquot was taken, filtered using $0.45 \mu \mathrm{m}$ membrane filter and analyzed using UV-VIS spectrophotometer at $271 \mathrm{~nm}$. An equal volume of dissolution media was replaced to maintain the sink condition of the dissolution media.

\section{RESULT AND DISCUSSION}

Microspherical carrageenan aerogel particles were prepared with an average surface area of $100 \pm 5 \mathrm{~m}^{2} \cdot \mathrm{g}^{-1}$ (Fig. 1). The pore volume and pore sizes were $0.23 \mathrm{~cm}^{3} \cdot \mathrm{g}^{-1}$ and $9.6 \mathrm{~nm}$, respectively. The average particle size of the prepared microparticles was $10 \mu \mathrm{m}$. The true, bulk, and tapped density were $1.64,0.14$, and $0.21 \mathrm{~g} \cdot \mathrm{cm}^{-3}$, respectively. The average zeta potential was $-37.70 \pm 1.57 \mathrm{mV}$ (Alnaief et al., 2018).

\section{Drug content}

Table 1 shows the average drug content of the prepared formulations. For both preparations, the drug content was exceeding $70 \%$, yet some loss of meloxicam was occurred. While atorvastatin maintained the same initial quantity in the sample, the drug content does not reflect drug loading. Loading efficiency can be evaluated through release profiles.

\section{Physicochemical characterization}

\section{Fourier transform-infrared}

Figure 2 shows the Fourier transform-infrared (FTIR) spectra of sample S1 loaded with meloxicam (M-S1) and atorvastatin (A-S1) compared with the corresponding PM. As it can be seen, no interaction occurred between meloxicam and the carrier and the functional groups of both the drug and the polymer were kept during formulation. While FTIR spectroscopy of sample S1 loaded with $10 \%$ atorvastatin (A-S1) with the corresponding PM, shows a slight difference in the FTIR peaks, including an increase in the intensity peaks at 1,219 and $1,074 \mathrm{~cm}^{-1}$ related to the $\mathrm{S}=\mathrm{O}$ of sulfate esters and glycosidic linkage of the Carrageenan polymer. This can be attributed to a physical interaction between the drug and the polymer.

\section{Powder X-ray diffraction}

The powder X-ray diffraction (PXRD) pattern of meloxicam and atorvastatin loaded aerogel was compared with

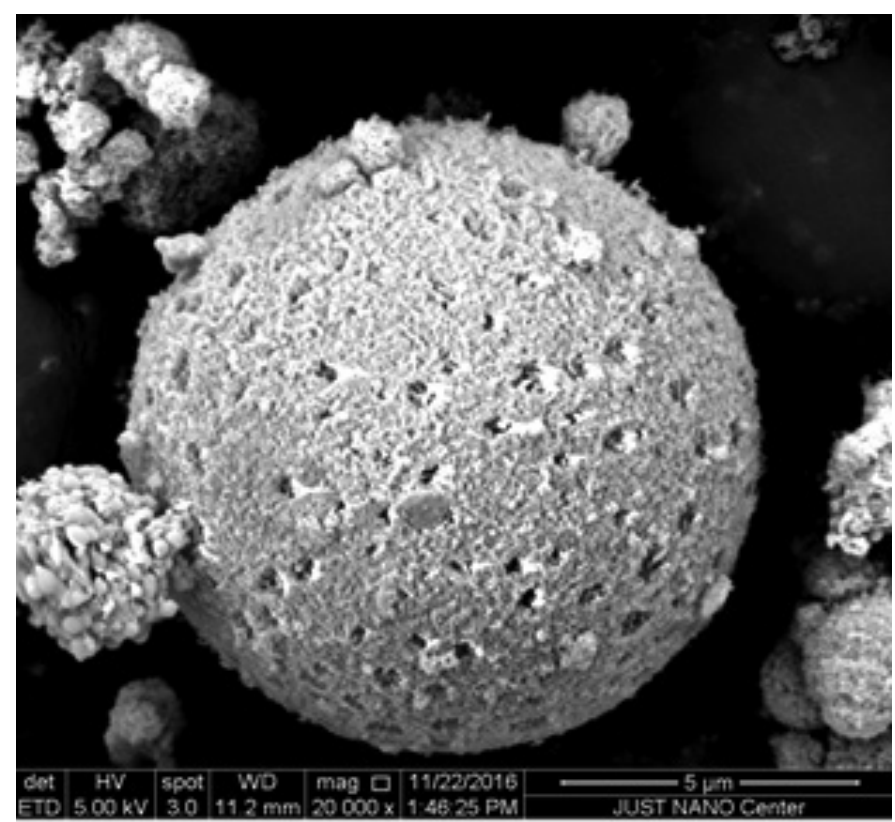

Figure 1. Microspherical carrageenan aerogel.

Table 1. Drug loading results.

\begin{tabular}{lcc}
\hline Sample & Drug content & SD \\
\hline Meloxicam (S1) & $75 \%$ & 5.05 \\
Atorvastatin (S1) & $100.2 \%$ & 2.52 \\
\hline
\end{tabular}



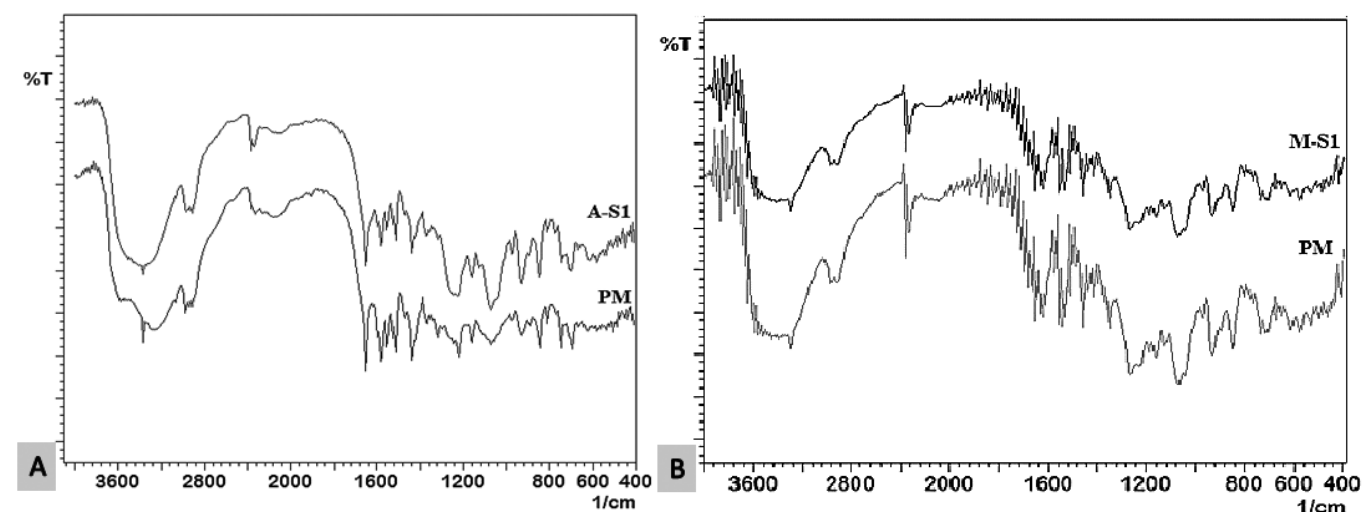

Figure 2. FTIR spectrum of (A) sample (A-S1) loaded with 10\% Atorvastatin, and (B) sample (M- S1) loaded with 10\% meloxicam compared with the corresponding PM.

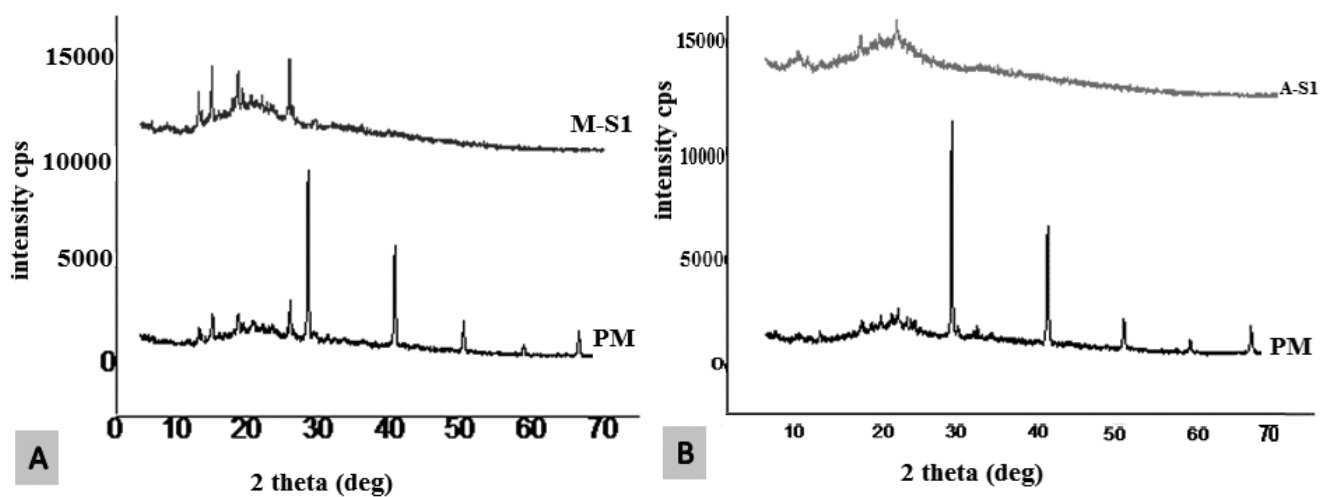

Figure 3. PXRD pattern of (A) sample (M-S1) loaded with $10 \%$ meloxicam and (B) sample (A-S1) loaded with $10 \%$ Atorvastatin compared with the corresponding PM.

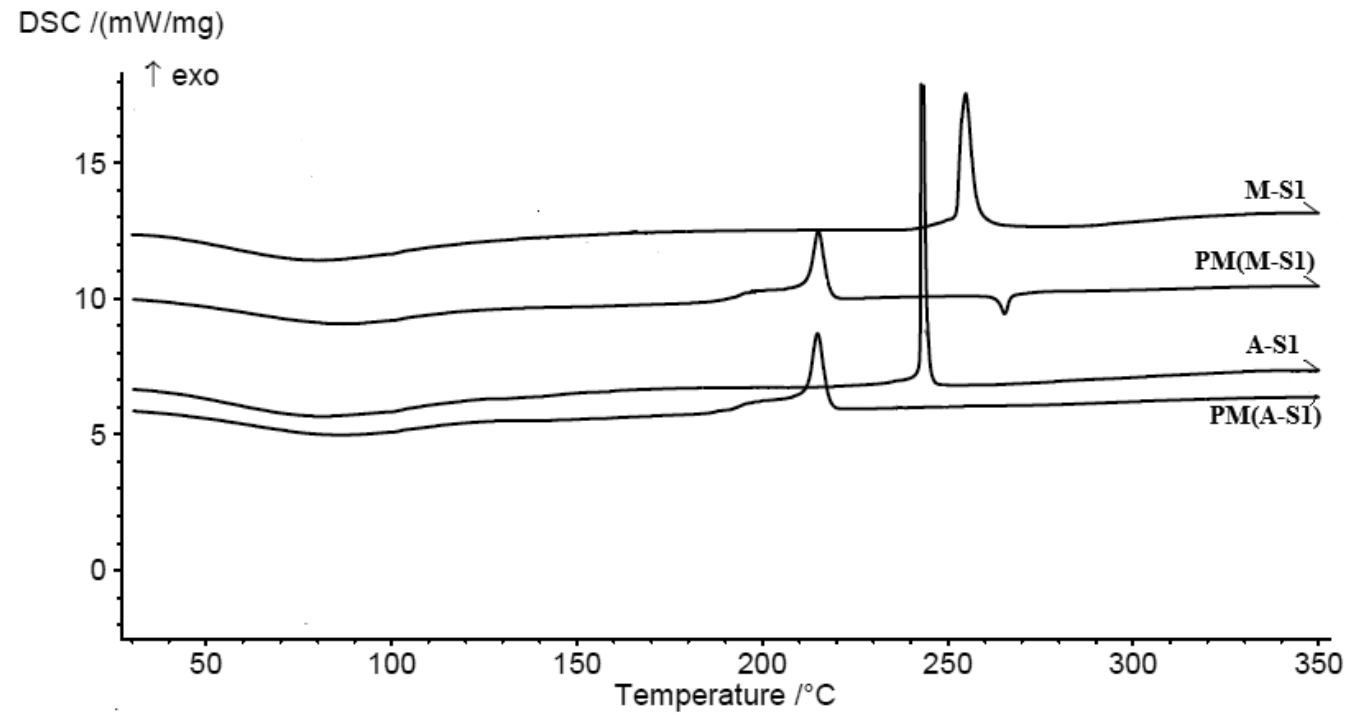

Figure 4. DSC thermograms of sample (A-S1) loaded with $10 \%$ Atorvastatin, and sample (M-S1) loaded with $10 \%$ meloxicam compared with the corresponding PM. 


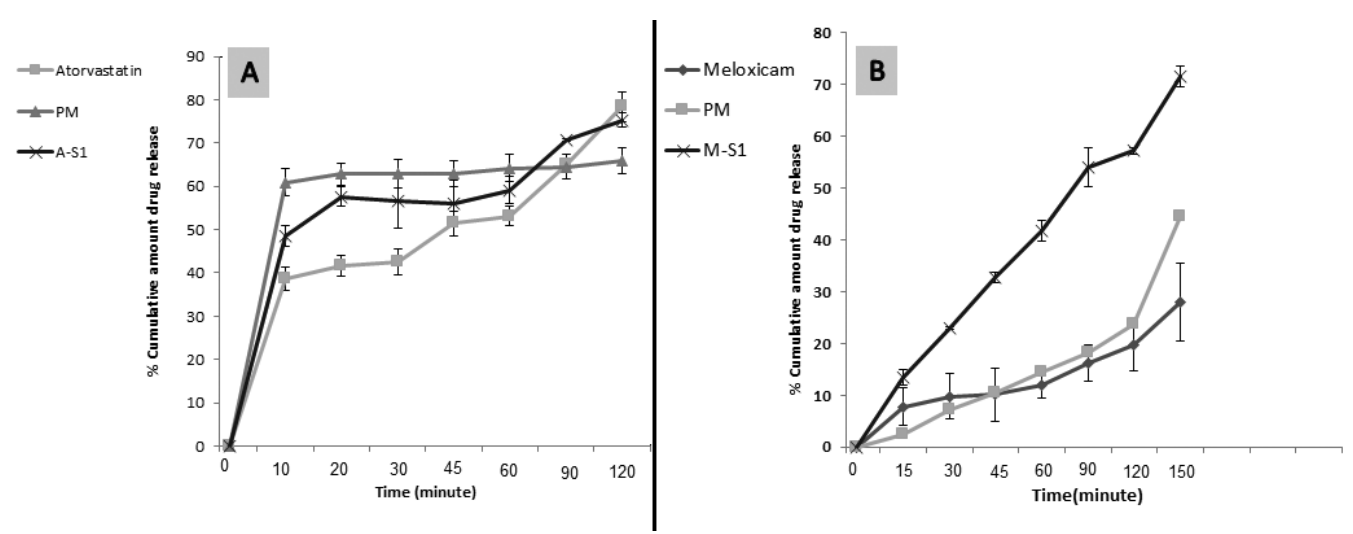

Figure 5. In vitro release profile of (A) sample A-S1 loaded with 10\% Atorvastatin, and (B) sample (M-S1) loaded with $10 \%$ meloxicam compared with corresponding PM.

the PM as shown in Figure 3, it indicated that the crystalline peaks of the Carrageenan polymer disappeared due its conversion from the crystalline to the amorphous form. However, the crystalline peaks of both drugs were preserved, meaning that the drug keeps its crystallinity.

\section{Thermal analysis}

The DSC thermogram of pure meloxicam was characterized by a single, sharp, and endothermic peak at $259.3^{\circ} \mathrm{C}$ which corresponds to the melting point of pure meloxicam and confirming its crystallinity. Another exothermic peak was observed at $265^{\circ} \mathrm{C}$ which indicates that meloxicam decomposes after melting, as was reported by Saleem and Bala (2010). Other previous studies reported that meloxicam has a melting point of $257.38^{\circ} \mathrm{C}$ (Kumar and Mishra, 2006). Also, El-Badry (2011) reported a meloxicam melting point at $262^{\circ} \mathrm{C}$ and Ghareeb (2009) reported a melting point of $257^{\circ} \mathrm{C}$ (El-Badry, 2011; Ghareeb et al., 2009). The DSC thermogram of sample S1 loaded with meloxicam compared with its corresponding PM is shown in Figure 4, the melting peak of meloxicam is completely disappeared in the prepared formulation. DSC thermogram of ATC (atorvastatin) characterized by a sharp endothermic peak at $157.5^{\circ} \mathrm{C}$ was attributed to the melting point of atorvastatin; this indicated the crystalline nature of the drug as it has been previously reported (Bathool et al., 2012; Zhang et al., 2009). The DSC result of sample S1 loaded with atorvastatin and the corresponding PM, the endothermic peak of the drug cannot be seen in the PM, this is related to the dilution of the drug powder. These results were indicative that the thermal analysis was not enough to evaluate the drug physical form inside the microspherical carrageenan particle.

In vitro release study

Meloxicam showed a very low dissolution rate, and by preparing the PM with the Carrageenan polymer, the release was slightly affected (Fig. 5). Sample S1 loaded with meloxicam showed that the release was significantly enhanced. In contrast, sample PM not significantly enhance the release. This means that the release of meloxicam not affected by the presence of the hydrophilic polymer Carrageenan, and the enhancement related to the properties of the prepared aerogels, where the sticky meloxicam drug dispersed through the small particle size of the prepared microparticles.
De-aggregation of meloxicam and physical entrapment of the drug physically in the pores of the particle can be used to explain such results as previously reported by Obaidat et al. (2017).

The in vitro release was performed for atorvastatin, sample S1 loaded sample compared with the corresponding PM. As it is shown in $\mathrm{x} 15$, no significant effect observed in the release profile of atorvastatin; the slight enhancement in the release with both of the PM and the sample can be related to the wettability effect of the hydrophilic polymer Carrageenan.

The slight difference between the PM and the loaded formulation can be related to the physical interaction that may occur between the drug and the Carrageenan polymer as indicated by the FTIR spectra (Fig. 2). Yet, lack of significant difference between the PM and the prepared samples may be indicative of a failure of loading of the drug inside the particle.

\section{CONCLUSION}

Successful loading of meloxicam in prepared Carrageenan microspherical aerogel particles was achieved. Significant enhancement in the release profile of meloxicam after loading in the Carrageenan aerogel can be related to de-aggregation of meloxicam inside the particle. On the other hand, atorvastatin model drug showed no significant changes in the release profile with the presence of possible interaction between the drug and the polymer as shown by FTIR spectra. Results were indicative of a failure in the loading of atorvastatin inside the carrageenan particle in the used experimental processing parameters.

\section{ACKNOWLEDGMENTS}

The authors would like to acknowledge Scientific Research Funds (SRF) at Ministry of Higher Education (Amman, Jordan) for funding this project (MPH/2/15/2013), Deanship of Research at Jordan University of Science and Technology (JUST) for analysis and administrative support.

\section{REFERENCES}

Alnaief M. Process development for production of aerogels with controlled morphology as potential drug carrier systems. Doctoral dissertation, Technische Universität Hamburg, Hamburg, Germany, 2011.

Alnaief M, Obaidat R, Mashaqbeh H. Effect of processing parameters on preparation of carrageenan aerogel microparticles. Carbohydr Polym, 2018; 180:264-75. 
Barros A, Quraishi S, Martins M, Gurikov P, Subrahmanyam R, Smirnova I, Duarte Ana Rita C, Reis Rui L. Hybrid alginate-based cryogels for life science applications. Chemie Ingenieur Technik, 2016; 88(11):1770-8

Bathool A, Vishakante GD, Khan MS, Shivakumar H. Development and characterization of atorvastatin calcium loaded chitosan nanoparticles for sustain drug delivery. Adv Mat Lett, 2012; 3(6):466-70.

Campo VL, Kawano DF, da Silva DB, Carvalho I. Carrageenans: biological properties, chemical modifications and structural analysis-a review. Carbohydr Polym, 2009; 77(2):167-80.

Dafe A, Etemadi H, Zarredar H, Mahdavinia GR. Development of novel carboxymethyl cellulose/k-carrageenan blends as an enteric delivery vehicle for probiotic bacteria. Int J Biol Macromol, 2017; 97:299-307.

El-Aassar MR, El Fawal GF, Kamoun EA, Fouda MMG. Controlled drug release from cross-linked $\kappa$-carrageenan/hyaluronic acid membranes. Int J Biol Macromol, 2015; 77:322-31.

Dissolution Methods. 2018. Available via https://www. accessdata.fda.gov/scripts/cder/dissolution/dsp_SearchResults.cfm (Accessed 25 October 2018).

El-Badry M. Physicochemical characterization and dissolution properties of meloxicam-gelucire 50/13 binary systems. Sci Pharm, 2011; 79(2):375-86.

García-González CA, Alnaief M, Smirnova I. Polysaccharidebased aerogels - promising biodegradable carriers for drug delivery systems. Carbohydr Polym, 2011; 86(4):1425-38.

García-González CA, Jin M, Gerth J, Alvarez-Lorenzo C Smirnova I. Polysaccharide-based aerogel microspheres for oral drug delivery. Carbohydr Polym, 2015; 117:797-806.

Ghareeb MM, Abdulrasool AA, Hussein AA, Noordin MI Kneading technique for preparation of binary solid dispersion of meloxicam with poloxamer 188. AAPS Pharm Sci Tech, 2009; 10(4):1206-15.

Gu J, Yang S, Ho EA. Biodegradable film for the targeted delivery of siRNA-loaded nanoparticles to vaginal immune cells. Mol Pharm, 2015; 12(8):2889-903.

Guan J, Li L, Mao S. Applications of carrageenan in advanced drug delivery. Seaweed Polysaccharide. Elsevier, Amsterdam, Netherlands, pp 283-303, 2017.

Gurikov P, Smirnova I. Amorphization of drugs by adsorptive precipitation from supercritical solutions: a review. J Supercrit Fluids, 2018; 132:105-25.

Hanawa T, Masuda N, Mohri K, Kawata K, Suzuki M, Nakajima S. Development of patient-friendly preparations: preparation of a new allopurinol mouthwash containing polyethylene(oxide) and carrageenan. Drug Dev Ind Pharm, 2004; 30(2):151-61.

Hezaveh H, Muhamad II. The effect of nanoparticles on gastrointestinal release from modified $\kappa$-carrageenan nanocomposite hydrogels. Carbohydr Polym, 2012; 89(1):138-45.

Jonganurakkun B, Nodasaka Y, Sakairi N, Nishi N. DNAbased gels for oral delivery of probiotic bacteria. Macromol Biosci, 2006; 6(1):99-103.

Karimi MH, Mahdavinia GR, Massoumi B. pH-controlled sunitinib anticancer release from magnetic chitosan nanoparticles crosslinked with $\kappa$-carrageenan. Mater Sci Eng C, 2018; 91:705-14.

Kumar SGV, Mishra DN. Preparation and evaluation of solid dispersion of meloxicam with skimmed milk. Yakugaku Zasshi, 2006; 126(2):93-7.

Li L, Ni R, Shao Y, Mao S. Carrageenan and its applications in drug delivery. Carbohydr Polym, 2014; 103:1-11.

Ling G, Zhang T, Zhang P, Sun J, He Z. Nanostructured lipidcarrageenan hybrid carriers (NLCCs) for controlled delivery of mitoxantrone hydrochloride to enhance anticancer activity bypassing the BCRP-mediated efflux. Drug Dev Ind Pharm, 2016; 42(8):1351-9.

Liu J, Zhan X, Wan J, Wang Y, Wang C. Review for carrageenanbased pharmaceutical biomaterials: favourable physical features versus adverse biological effects. Carbohydr Polym, 2015; 121:27-36.

Luger P, Daneck K, Engel W, Trummlitz G, Wagner K. Structure and physicochemical properties of meloxicam, a new NSAID. Eur J Pharm Sci, 1996; 4(3):175-87.
Maleki H. Recent advances in aerogels for environmental remediation applications: a review. Chem Eng J, 2016; 300:98-118.

Maleki H, Durães L, García-González CA, del Gaudio P, Portugal A, Mahmoudi M. Synthesis and biomedical applications of aerogels: Possibilities and challenges. Adv Colloid Interface Sci, 2016; 236:1-27.

Maleki H, Hüsing N. Current status, opportunities and challenges in catalytic and photocatalytic applications of aerogels: environmental protection aspects. Appl Catal B Environ, 2018; 221:530-55.

Martins M, Barros AA, Quraishi S, Gurikov P, Raman SP, Smirnova I, Duarte AR, Reis RL. Preparation of macroporous alginatebased aerogels for biomedical applications. J Supercrit Fluids, 2015; 106:152-9.

Necas J, Bartosikova L. Carrageenan: a review. Vet Med, 2013; 58(4):187-205.

Obaidat R, Al-taani B, Al-quraan H. Effect of selected polymer on dissolution and stabilization of amorphous form of meloxicam. Int $\mathrm{J}$ Pharm Pharm Sci, 2017; 9(9):33-42.

Obaidat RM, Alnaief M, Mashaqbeh H. Investigation of carrageenan aerogel microparticles as a potential drug carrier. AAPS Pharm Sci Tech, 2018; 19(5):2226-36.

Patil RT, Speaker TJ. Water-based microsphere delivery system for proteins. J Pharm Sci, 2000; 89(1):9-15.

de Queiroz Ribeiro N, Costa MC, Magalhães TF, Carneiro HC, Oliveira LV, Fontes AC, Santos JR, Ferreira GF, de Sousa Araujo GR, Alves V, Frases S. Atorvastatin as a promising anticryptococcal agent. Int J Antimicrob Agents, 2017; 49(6):695-702.

Rowe RC, Sheskey PJ, Owen SC (eds.). Handbook of pharmaceutical excipients. 6th edition, Pharmaceutical Press, London, UK, 2009.

Saleem M, Bala S. Formulation and evaluation of meloxicam solid dispersion incorporated topical gels. Int J Pharma Bio Sci, 2010;1 (3):1-9.

Santo VE, Frias AM, Carida M, Cancedda R, Gomes ME, Mano JF, Reis RL. Carrageenan-based hydrogels for the controlled delivery of PDGF-BB in bone tissue engineering applications. Biomacromolecules, 2009; 10(6):1392-401.

Smirnova I. Aerogels: current status and challenges for the future. J Supercrit Fluids, 2015; 106:1.

Sonje VM, Kumar L, Meena CL, Kohli G, Puri V, Jain R, Bansal AK, Brittain HG. Chapter 1-atorvastatin calcium. Profiles of drug substances, excipients and related methodology. Academic Press, vol. 35, pp 1-70, 2010.

Stergar J, Maver U. Review of aerogel-based materials in biomedical applications. J Sol-Gel Sci Technol, 2016; 77(3):738-52.

Tan IS, Lee KT. Immobilization of $\beta$-glucosidase from Aspergillus niger on $\kappa$-carrageenan hybrid matrix and its application on the production of reducing sugar from macroalgae cellulosic residue. Adv Biofuels Chem Algae, 2015; 184:386-94.

Ulker Z, Erkey C. An emerging platform for drug delivery: aerogel based systems. J Controlled Release 2014; 177:51-63.

Varghese JS, Chellappa N, Fathima NN. Gelatin-carrageenan hydrogels: role of pore size distribution on drug delivery process. Colloids Surf B Biointerfaces, 2014; 113:346-51.

Zhang H-X, Wang J-X, Zhang Z-B, Le Y, Shen Z-G, Chen J-F. Micronization of atorvastatin calcium by antisolvent precipitation process. Int J Pharm, 2009; 374(1-2):106-13.

How to cite this article:

Alnaief M, Obaidat R, Mashaqbeh H. Loading and evaluation of meloxicam and atorvastatin in carrageenan microspherical aerogels particles. J Appl Pharm Sci, 2019; 9(01):083-088. 